\title{
Early mobilization of critically ill adults: a survey of knowledge, perceptions and practices of Canadian physicians and physiotherapists
}

\author{
Karen K.Y. Koo MD MSc, Karen Choong MB MSc, Deborah J. Cook MD MSc, \\ Margaret Herridge MD MPH, Anastasia Newman PT MSc, Vincent Lo PT, Gordon Guyatt MD MSc, \\ Fran Priestap MSc, Eileen Campbell CCRC, Karen E.A. Burns MD MSc, François Lamontagne MD MSc, \\ Maureen O. Meade MD MSc; the Canadian Critical Care Trials Group
}

\section{Abstract}

Background: The promotion of early mobilization following critical illness is tempered by national reports of patient and institutional barriers to this approach. We carried out a survey to assess current knowledge, perceptions and practices of Canadian physicians and physiotherapists with respect to acquired weakness and early mobilization in adults in the intensive care unit (ICU).

Methods: We conducted a cross-sectional, self-administered postal survey among critical care physicians and physiotherapists in all 46 academic ICUs in Canada in 2011-2012. To identify all physicians and physiotherapists working in the ICUs, we contacted division heads and senior physiotherapists by telephone or email. We designed, tested and administered a questionnaire with the following domains: knowledge of ICU-acquired weakness and early mobilization; personal views of, perceived barriers to and adequacy of technical skills for early mobilization; assessments for initiation of early mobilization and permissible activity levels by patient physiologic characteristics, diagnoses and therapies; staffing issues; and sedation practices.

Results: The overall response rate was $71.3 \%$ (311/436); it was 64.2\% (194/302) among physicians and 87.3\% (117/134) among physiotherapists. A total of 214 respondents $(68.8 \%)$ underestimated the incidence of ICU-acquired weakness in the general medicalsurgical ICU population, and $186(59.8 \%)$ stated they had insufficient knowledge or skills to mobilize patients receiving mechanical ventilation. Excessive sedation, medical instability, limited staffing, safety concerns, insufficient guidelines and insufficient equipment were common perceived barriers to early mobilization.

Interpretation: Physicians and physiotherapists in the ICU underestimated the incidence of ICU-acquired weakness and felt inadequately trained to mobilize patients receiving mechanical ventilation. We identified multiple modifiable barriers to early mobilization at the institutional, health care provider and patient levels that need to be addressed when designing mobilization programs for critically ill adults.

\footnotetext{
C ritically ill patients are often confined to bed rest, ${ }^{1}$ and interventions to restore acute organ function in the intensive care unit (ICU) are typically prioritized ahead of efforts to preserve physical and mental function. Early mobilization involves timely progression during critical illness through a series of activities from active range of motion to full ambulation. Prospective observations and randomized controlled trials have shown that early mobilization is safe and feasible $^{2-5}$ and may improve functional outcomes following critical illness. ${ }^{6,7}$

The promotion of early mobilization is tempered by national survey reports of patient and institutional barriers to this
}

approach. ${ }^{8-15}$ The relative importance of these perceived barriers to early mobilization is unclear. Moreover, how they relate to the potential barriers posed by health care providers, including their level of knowledge and abilities, has not been investigated.

Competing interests: None declared.

This article has been peer reviewed.

Correspondence to: Karen Koo, karen.koo@swedish.org

CMAJ Open 2016. DOI:10.9778/cmajo.20160021 
We designed, tested and administered a postal survey for Canadian critical care physicians and physiotherapists to assess their knowledge of acquired weakness and early mobilization in adults in the ICU, acute rehabilitation practices in the ICU setting, and perceived barriers to early mobilization at the institutional, health care provider and patient levels.

\section{Methods}

\section{Survey development}

The study was conducted from January 2011 to January 2012. To generate relevant and topical survey items, we searched the literature for publications on mobilization practices in the ICU. Two investigators (K.K.Y.K., K.C.) independently searched 7 electronic bibliographic databases from their inception to April 2010: MEDLINE, Embase, the Cochrane Central Register of Controlled Trials, CINAHL, the Allied and Complementary Medicine Database, the Physiotherapy Evidence Database and REHABDATA. The MeSH subject heading "Early Ambulation" or the text words "early" or "immediate" were used in combination with "mobilization," "ambulation," "exercise," "rehabilitation" or "physiotherapy." We limited citations by using the terms "intensive care," "ICU," "critical care" and "critically ill." A panel of 26 content experts at the 3rd International Physical Medicine and Rehabilitation meeting (New Orleans, May 2010) reviewed survey items under the themes of knowledge, perspectives and practice until no new constructs emerged. Two focus groups including 25 critical care investigators of the Canadian Critical Care Trials Group and 6 experts in critical care medicine and rehabilitation research condensed 70 survey items to 28 without excluding important constructs within the following domains: knowledge of ICU-acquired weakness and early mobilization; personal views of, perceived barriers to and adequacy of technical skills for early mobilization; assessments for initiation of early mobilization and permissible activity levels by patient physiologic characteristics, diagnoses and therapies; staffing issues; and sedation practices. The final survey included various question formats (true/false, yes/no, nominal, ordinal and Likert scales) but no open-ended questions (Appendix 1, available at www.cmajopen.ca/content/ 4/3/E448/suppl/DC1).

\section{Survey testing}

The interpretation of each survey item was assessed by 10 methodologists. Ten additional clinicians, including critical care nurses, therapists and physicians, reviewed the survey to ascertain its ease of administration, flow and salience. Next, we used a modified clinical sensibility form ${ }^{16}$ to evaluate the comprehensiveness, clarity and face validity among 12 content experts with no previous role in the development or testing of the survey. After administering the survey to 20 respondents, including critical care nurses, therapists and physicians, on 2 separate occasions, 2 weeks apart, we estimated interrater reliability using Cohen's $\kappa$, which exceeded 0.4 on each item, indicating moderate to excellent interrater reliability across items. ${ }^{17}$ We modified the survey based on these data to improve reliability, without further testing.

\section{Survey administration}

To identify all physicians and physiotherapists working in all 46 university-based ICUs across Canada (defined as academic ICUs with Royal College of Physician and Surgeon of Canada residency training programs in critical care medicine, which are uniformly "closed" units), we contacted division heads and senior physiotherapists by telephone or email. We reviewed hospital and provincial licensing websites for mailing addresses. Up to 3 surveys were mailed to each target respondent.

\section{Statistical analysis}

We report descriptive statistics including proportions, means (and standard deviations [SDs]) or mode, where appropriate. Separate multivariate logistic regression analyses were performed to evaluate factors associated with clinician knowledge of ICU-acquired weakness, factors associated with clinicians who felt well trained and informed to mobilize patients receiving mechanical ventilation, and factors associated with clinician perception that early mobilization is very important or critical. We used $\chi^{2}$ tests to compare proportions. Multivariate logistic regression was used to test for associations between the dependent variables and predetermined independent variables in the regression models, including clinician discipline (medicine or physiotherapy), years of practice ( $<5 \mathrm{yr}, 5-20 \mathrm{yr}$ or $>20 \mathrm{yr}$ ), ICU type (medical-surgical, cardiovascular, trauma, neurologic or burn), the presence of an early mobility champion within the ICU, ICU size ( $<15$ beds, $15-20$ beds or $>20$ beds) and region of practice (Eastern, Central, Prairies or Western). We used SAS version 9.3 to conduct the statistical analyses. A $p$ value of less than 0.05 was considered statistically significant.

The study was approved by the research ethics boards of the University of Western Ontario and the Lawson Health Research Institute.

\section{Results}

We mailed questionnaires to 315 physicians and 140 physiotherapists. Of the 455 recipients, 8 were no longer in practice, and 9 received the survey in duplicate; in addition, 2 surveys were sent as test entries. Of the remaining 436 recipients, 311 (71.3\%) responded, including 194/302 physicians (64.2\%) and $117 / 134$ physiotherapists $(87.3 \%)$ (Table 1$)$.

Respondents from all 46 ICUs participated. Most (269 [86.5\%]) practised in mixed medical and surgical ICUs, with additional representation from specialized cardiovascular recovery (134 [43.1\%]), trauma (126 [40.5\%]), neurologic (122 [39.2\%]) and burn (60 [19.3\%]) units.

\section{Knowledge}

Overall, 214 respondents $(68.8 \%)$ underestimated the incidence of ICU-acquired weakness in general medical and surgical ICUs based on prospective observational studies $(>40 \%),{ }^{18-22}$ irrespective of their discipline, years of clinical experience, presence of an early mobility champion within their ICU or region of practice (Table 2). Similar proportions of physicians $(30.4 \%)$ and physiotherapists (32.5\%) answered 
correctly. About two-thirds of the respondents (209 [67.2\%]) reported being familiar with the current literature on early mobilization in the ICU; the proportions of physicians and physiotherapists were $67.5 \%$ and $66.7 \%$, respectively. A total of 125 physicians (64.4\%) and 67 physiotherapists (57.3\%) responded correctly to 5 true/false questions related to clinical trials of early mobilization in the $\operatorname{ICU}^{2,4-6}(p=0.07)$.

Over half of the respondents (186 [59.8\%]) reported that they lacked sufficient knowledge or training to mobilize patients receiving mechanical ventilation. The proportions of physicians and physiotherapists were $72.3 \%$ and $39.3 \%$, respectively. A total of 131 respondents (42.1\%) reported they were somewhat trained and informed, and $55(17.7 \%)$ reported they were not sufficiently trained or informed. Physiotherapists (71 [60.7\%]) were more likely than physicians (49 [25.2\%]) to believe that they were well trained and informed (absolute difference 35.2 , 95\% confidence interval [CI] 32.4-38).

\section{Perceptions}

A total of 214 respondents (68.8\%) believed that early mobilization is crucial or very important in the care of critically ill patients. Physiotherapists were more likely than physicians to believe that early mobilization is crucial or very important (odds ratio [OR] 2.8, 95\% CI 1.3-5.6, $p=0.006$ ). Respondents practising in ICUs with fewer than 15 beds (compared with those practising in ICUs with more than 20 beds) were less likely to believe that early mobilization was crucial or very important (OR 0.4, 95\% CI 0.2-0.8, $p=0.014$ ), as were those practising in ICUs without an early mobility champion (compared with those practising in ICUs with an early mobilization champion) (OR 0.3, 95\% CI 0.2-0.5, p<0.001)

Over half of the respondents (185 [59.5\%]) believed mobilization should begin as soon as possible following ICU

Table 1: Characteristics of the survey respondents

\begin{tabular}{|lc|}
\hline Characteristic & $\begin{array}{c}\text { No. (\%) of } \\
\text { respondents } \\
(n=311)\end{array}$ \\
\hline Discipline & \\
\hline Medicine & $194(62.4)$ \\
\hline Physiotherapy & $117(37.6)$ \\
\hline Type of practice* & \\
\hline Medical and/or surgical ICU & $269(86.5)$ \\
\hline Cardiovascular ICU & $134(43.1)$ \\
\hline Trauma ICU & $126(40.5)$ \\
\hline Neurological ICU & $122(39.2)$ \\
\hline Burn ICU & $60(19.3)$ \\
\hline Clinical experience, yr & $90(28.9)$ \\
\hline$<5$ & $160(51.4)$ \\
\hline 5-20 & $61(19.6)$ \\
\hline$>20$ & \\
\hline $\begin{array}{l}\text { Note: ICU = intensive care unit. } \\
\text { *Some respondents practised in more than 1 type of ICU. }\end{array}$ \\
\hline
\end{tabular}

admission. However, a number of barriers to early mobilization were reported. The most common perceived institutional barriers were a lack of written guidelines or protocols, insufficient equipment and the need for physician orders before mobilization (Table 3). The most frequent perceived provider barriers were limited staffing (primarily physiotherapists and nurses) to routinely mobilize patients, safety concerns (primarily among nurses) and delays in recognizing patient eligibility (primarily among physicians and nurses (Table 4). The most important perceived barriers at the patient level were medical instability, excessive sedation and dislodgement of catheters or other devices (Table 5).

Over a third of the respondents (121 [38.9\%)] believed that patients with traumatic brain injury and increased intracranial pressure should be restricted to bed rest whereas those without raised intracranial pressures could ambulate (120 [38.6\%]). They felt that patients with delirium (73 respondents [23.5\%]), cervical spinal injury $(81[26.0 \%])$, thoracic-lumbar spinal injury $(87[28.0 \%]$ ) or acute myocardial infarction (within $24 \mathrm{~h}$ and with persistently elevated cardiac enzyme levels) (86 [27.6\%]) should be restricted to active range of motion. Most or all respondents believed activity restrictions were not necessary for patients with subacute myocardial infarction (within $24 \mathrm{~h}$ and with decreasing cardiac enzyme levels) (258 [83.0\%]), coagulopathy (304 [97.7\%]), thrombocytopenia (300 [96.5\%]), deep vein thrombosis (309 [99.4\%]), obesity (311 [100.0\%]) or frailty (311 [100.0\%]).

More restricted activity was considered necessary for patients with invasive monitoring devices or advanced lifesupport measures. Respondents would prescribe active range of motion for patients with a pulmonary artery catheter in situ (90 [28.9\%]) or receiving continuous renal replacement therapy $(168[54.0 \%])$, and bed rest for patients supported by intra-aortic balloon pumps (111 [35.7\%]), extracorporeal membrane oxygenation (86 [27.6\%]) or high-frequency oscillation (115 [37.0\%]).

Catheter location affected permissible levels of activity. A total of 191 respondents (61.4\%) would be comfortable allowing patients with arterial catheters inserted at the radial site to ambulate freely, and most (243 [78.1\%]) believed that patients with dialysis catheters inserted at subclavian sites could be permitted to ambulate during nondialysis periods. About onethird of respondents believed that patients with femoral central venous catheters (104 [33.4\%]) or femoral dialysis catheters (91 [29.3\%]) should be restricted to active range of motion. The use of chest tubes (244 respondents [78.4\%]), Foley urine catheters $(265[85.2 \%])$ or full-dose therapeutic anticoagulation (248 [79.7\%]) was generally not perceived to necessitate restricted activity.

Just over half of the respondents (168 [54.0\%]) believed that patients receiving minimal cardiovascular and respiratory support and with the ability to follow motor and verbal commands could be permitted to ambulate freely. As the level of cardiovascular support increased, fewer respondents were comfortable with allowing patients to ambulate, and more of them would restrict the maximal level of activity. A similar trend of greater restriction in activity level was observed as the amount of respi- 
ratory support increased. Respondents believed that patients receiving conventional ventilation with moderate pressure support or noninvasive positive-pressure ventilation could transfer from a bed to a chair (118 [37.9\%] and 132 [42.4\%] respondents, respectively). More respondents would permit full ambulation in patients receiving ventilation though a tracheostomy (191 [61.4\%]) than through an endotracheal tube (141 [45.3\%]). Most respondents (304 [97.7]) thought that patients with impaired cognition and inability to follow verbal commands should be restricted to passive range of motion.

\section{Practices}

Fifty-one physiotherapists (43.6\%) reported screening all critically ill patients for mobilization. Most physiotherapists (86 [73.5\%]) agreed that their initial assessment of each patient required a written medical order by a physician.
Most respondents believed that nurses (304 [97.7\%]) and physiotherapists (303 [97.4\%]) were the primary participants in acute rehabilitation; other participants included health care aides (196 respondents [63.0\%]), family members or home caregivers (86 [27.6\%]), occupational therapists (70 [22.5\%]), physicians (53 [17.0\%]) and respiratory therapists $(20[6.4 \%])$. Just over half of the respondents (169 [54.3\%]) reported at least 1 champion - commonly a physiotherapist (78/169 [46.2\%]) or physician $(65 / 169$ [38.5\%]) — who promoted mobilization through patient advocacy or quality-improvement initiatives.

Most physiotherapists (109 [93.2\%]) reported that they were available for full assessments and mobilization from 8 am to $5 \mathrm{pm}$ from Monday to Friday. About three-quarters (87 [74.4\%]) said they were not available to provide chest physiotherapy after $5 \mathrm{pm}$, and 77 (65.8\%) stated they would provide chest physiotherapy on the weekend. Of the 110 physiothera-

\begin{tabular}{|c|c|c|c|}
\hline \multirow[b]{2}{*}{ Incidence, \% } & \multicolumn{3}{|c|}{ No. (\%) of respondents } \\
\hline & $\begin{array}{l}\text { All clinicians } \\
\quad(n=311)\end{array}$ & $\begin{array}{l}\text { Physicians } \\
(n=194)\end{array}$ & $\begin{array}{l}\text { Physiotherapists } \\
\quad(n=117)\end{array}$ \\
\hline$<5$ & $4(1.3)$ & $2(1.0)$ & $2(1.7)$ \\
\hline $5-10$ & $30(9.6)$ & $13(6.7)$ & $17(14.5)$ \\
\hline $11-20$ & $59(19.0)$ & $43(22.2)$ & $16(13.7)$ \\
\hline $21-40$ & $100(32.2)$ & $68(35.0)$ & $32(27.4)$ \\
\hline$>40^{*}$ & 97 (31.2) & $59(30.4)$ & $38(32.5)$ \\
\hline Do not know & $13(4.2)$ & $4(2.1)$ & $9(7.7)$ \\
\hline No response & $8(2.6)$ & $5(2.6)$ & $3(2.6)$ \\
\hline
\end{tabular}

Table 3: Perceived institutional barriers* to early mobilization in the intensive care unit

\begin{tabular}{|lccc|}
\hline & & No. (\%) of respondents & \\
\cline { 2 - 4 } Institutional barrier & $\begin{array}{c}\text { All respondents } \\
(n=311)\end{array}$ & $\begin{array}{c}\text { Physicians } \\
(n=194)\end{array}$ & $\begin{array}{c}\text { Physiotherapists } \\
(n=117)\end{array}$ \\
\hline No written guidelines or protocols & $177(56.9)$ & $134(69.1)$ & $43(36.8)$ \\
\hline Insufficient equipment for early mobilization & $160(51.4)$ & $109(56.2)$ & $51(43.6)$ \\
\hline Physician orders required before mobilization & $126(40.5)$ & $72(37.1)$ & $54(46.2)$ \\
\hline No clinician champion or advocate & $88(28.3)$ & $71(36.6)$ & $17(14.5)$ \\
\hline Not enough physical space & $63(20.2)$ & $48(24.7)$ & $21(17.9)$ \\
\hline $\begin{array}{l}\text { Routine bed rest orders on admission to } \\
\text { intensive care unit }\end{array}$ & $50(16.1)$ & $29(14.9)$ & $4(3.4)$ \\
\hline $\begin{array}{l}\text { Perceived to be an expensive intervention by } \\
\text { administrators or unit leaders }\end{array}$ & $25(8.0)$ & $21(10.8)$ & $16(13.7)$ \\
\hline Other† & $25(8.0)$ & $9(4.6)$ & $58(49.6)$ \\
\hline None & $128(41.2)$ & $70(36.1)$ & \\
\hline $\begin{array}{l}* \\
\text { *Customs and behaviour patterns in respondent's work environment. } \\
\text { tIncluded lack of resources, no culture to promote, not supported by administrators. }\end{array}$ & & \\
\hline
\end{tabular}




\section{OPEN}

Research

\begin{tabular}{|c|c|c|c|c|c|c|}
\hline \multirow[b]{2}{*}{ Health care provider barrier } & \multicolumn{6}{|c|}{ Health care provider contributing to barrier; no. (\%) of respondents } \\
\hline & $\begin{array}{l}\text { Critical care } \\
\text { physician }\end{array}$ & Physiotherapist & $\begin{array}{l}\text { Registered } \\
\text { nurse }\end{array}$ & $\begin{array}{l}\text { Respiratory } \\
\text { therapist }\end{array}$ & $\begin{array}{c}\text { Referring } \\
\text { consultant/ } \\
\text { primary } \\
\text { surgeon }\end{array}$ & None \\
\hline $\begin{array}{l}\text { Limited staffing to routinely mobilize } \\
\text { patients }\end{array}$ & $5(1.6)$ & $241(77.5)$ & $182(58.5)$ & $92(29.6)$ & $7(2.2)$ & $36(11.6)$ \\
\hline $\begin{array}{l}\text { Early mobilization not perceived as a } \\
\text { priority }\end{array}$ & $156(50.2)$ & $30(9.6)$ & $168(54.0)$ & $71(22.8)$ & $62(19.9)$ & $85(27.3)$ \\
\hline $\begin{array}{l}\text { Early mobilization not supported by } \\
\text { some specific individuals }\end{array}$ & $55(17.7)$ & $15(4.8)$ & $117(37.6)$ & $31(10.0)$ & $31(10.0)$ & $141(45.3)$ \\
\hline $\begin{array}{l}\text { Lack of communication during bedside } \\
\text { rounds }\end{array}$ & $141(45.3)$ & $99(31.8)$ & $134(43.1)$ & $66(21.2)$ & $36(11.6)$ & $108(34.7)$ \\
\hline Lack of communication at shift change & $75(24.1)$ & $45(14.5)$ & $167(53.7)$ & $41(13.2)$ & $12(3.8)$ & $96(30.9)$ \\
\hline $\begin{array}{l}\text { Lack of coordination to facilitate early } \\
\text { mobilization }\end{array}$ & $83(26.7)$ & $143(46.0)$ & $166(53.4)$ & $113(36.3)$ & $29(9.3)$ & 99 (31.8) \\
\hline $\begin{array}{l}\text { Delayed recognition of suitable patients } \\
\text { to mobilize }\end{array}$ & $196(63.0)$ & $54(17.4)$ & $182(58.5)$ & $59(19.0)$ & $48(15.4)$ & $63(20.2)$ \\
\hline $\begin{array}{l}\text { Lack of decision-making authority to } \\
\text { initiate early mobilization }\end{array}$ & $83(26.7)$ & $96(30.9)$ & $82(26.4)$ & $35(11.2)$ & $24(7.7)$ & $126(40.5)$ \\
\hline $\begin{array}{l}\text { Conflicting perceptions about suitability } \\
\text { of early mobilization }\end{array}$ & $138(44.4)$ & $93(29.9)$ & $181(58.2)$ & $64(20.6)$ & 45 (14.5) & $86(27.6)$ \\
\hline $\begin{array}{l}\text { Safety concerns about early } \\
\text { mobilization }\end{array}$ & $95(30.5)$ & $89(28.6)$ & $200(64.3)$ & $87(28.0)$ & 37 (11.9) & $75(24.1)$ \\
\hline $\begin{array}{l}\text { Inadequate training to facilitate early } \\
\text { mobilization }\end{array}$ & 93 (29.9) & $83(26.7)$ & $161(51.8)$ & 97 (31.2) & 37 (11.9) & $114(36.6)$ \\
\hline Other & $3(1.0)$ & $5(1.6)$ & $3(1.0)$ & $2(0.6)$ & $1(0.3)$ & 297 (95.5) \\
\hline
\end{tabular}

\begin{tabular}{|lccc|}
\hline \multicolumn{4}{|c|}{ Table 5: Perceived patient barriers to early mobilization in the intensive care unit } \\
\hline & \multicolumn{3}{|c|}{ No. (\%) of respondents } \\
\cline { 2 - 4 } Patient barrier & $\begin{array}{c}\text { All clinicians } \\
(n=311)\end{array}$ & $\begin{array}{c}\text { Physicians } \\
(n=194)\end{array}$ & $\begin{array}{c}\text { Physiotherapists } \\
(n=117)\end{array}$ \\
\hline Medical instability & $257(82.6)$ & $150(77.3)$ & $107(91.4)$ \\
\hline Excessive sedation & $187(60.1)$ & $112(57.7)$ & $75(64.1)$ \\
\hline $\begin{array}{l}\text { Risk of dislodgement of } \\
\text { devices or lines }\end{array}$ & $130(41.8)$ & $106(54.6)$ & $24(20.5)$ \\
\hline Obesity & $105(33.8)$ & $75(38.6)$ & $30(25.6)$ \\
\hline Cognitive impairment & $98(31.5)$ & $72(37.1)$ & $17(14.5)$ \\
\hline Endotracheal intubation & $88(28.3)$ & $71(36.6)$ & $14(12.0)$ \\
\hline Physical restraints & $64(20.6)$ & $50(25.8)$ & $20(17.1)$ \\
\hline Inadequate analgesia & $43(13.8)$ & $23(11.8)$ & $4(1.7)$ \\
\hline Frailty & $41(13.2)$ & $39(20.1)$ & $13(11.1)$ \\
\hline Inadequate nutritional status & $8(2.6)$ & $4(2.1)$ & $3(2.6)$ \\
\hline Other* & $25(8.0)$ & $12(6.2)$ & $3(1.5)$ \\
\hline None & $6(1.9)$ & & \\
\hline *Included anxiety, patient not motivated, extracorporeal membrane oxygenation and dialysis. & \\
\hline
\end{tabular}


pists who responded to the question regarding work status, 51 (46.4\%) worked full time and 59 (53.6\%) worked part time. Physiotherapists had an average daily workload of 6 patients in the ICU (SD 3, range 0-15) and 10 patients on the ward (SD 3, range 0-20).

A minority of respondents reported that daily interruption of sedation infusions was used routinely (106 [34.1\%]) or frequently (61 [19.6\%]). Just over half of the physicians (108 [55.7\%]) thought that standardized sedation scales or protocols were titrated to the patient's activity level, whereas about onethird of the physiotherapists stated that standardized sedation scales were never titrated to activity level (40 [34.2\%]) or were unsure whether they were used at all (45 [38.5\%]).

\section{Interpretation}

Our results highlight significant gaps in knowledge of ICUacquired weakness among Canadian physicians and physiotherapists: $69 \%$ of our respondents underestimated the incidence of ICU-acquired weakness in the general medical-surgical population. Knowledge deficits were not associated with level of experience, region of practice or discipline of practice in our regression analysis. In addition, more than half of the respondents reported that they lacked sufficient knowledge or training to mobilize patients receiving mechanical ventilation. Although physiotherapists were 2.5 times more likely to feel well trained and well informed than physicians, they depended on physician orders to initiate early mobilization, and $39 \%$ of them reported that their skills and knowledge were inadequate. These results suggest that further education to increase knowledge and improve technical skills is necessary to facilitate early mobilization in the ICU.

Reported improvements in functional outcomes and cost savings in prospective studies of early mobilization for critically ill patients have heightened the awareness of ICUacquired weakness. ${ }^{23,24}$ We observed strong enthusiasm for early mobilization, particularly among physiotherapists and where mobility champions existed. Mobility can be limited by safety concerns, delays in the recognition of suitable patients, low prioritization for this aspect of care, and poor interdisciplinary communication and coordination. Like other investigators, we found that excessive sedation, ${ }^{15,25}$ medical instability, ${ }^{10,15,25}$ lack of physician orders, ${ }^{10,14}$ insufficient staffing ${ }^{11-15,26}$ and insufficient equipment ${ }^{8,15,27}$ were important barriers to early mobilization. A multidisciplinary team and portable equipment (including cardiac monitors, pulse oximeters, battery-powered ventilators, bag-valve masks with supplemental oxygen, suction devices, poles and wheelchairs) are required to deliver physiotherapy safely. ${ }^{24,26,28}$

\section{Strengths and limitations}

Strengths of this survey include development of an interdisciplinary instrument by a broad range of clinical and scientific experts in rehabilitation research, physiotherapy, nursing, neurology, clinical epidemiology and critical care. We used several evidence-based design and incentive-based strategies to achieve a high response rate and reduce nonresponder bias. ${ }^{16}$
The survey instrument also has good intrarater reliability and excellent face validity.

There are limitations to our survey. The sampling frame included all physicians and physiotherapists who practise in university-affiliated hospitals in Canada. Our results may not reflect the perspectives of clinicians working in communitybased practices, other disciplines or other countries. However, our findings of a lack of protocols to initiate activity ${ }^{14}$ and the limited resources and personnel to mobilize patients ${ }^{11-15}$ parallel results in other national surveys. Finally, like any survey of stated practice, our findings may not reflect actual practice.

\section{Conclusion}

Most of our respondents believed that early mobilization of critically ill patients is important but cited numerous important barriers at the institution, health care provider and patient levels. Providing timely rehabilitation in the ICU setting was perceived to be challenged primarily by significant gaps in knowledge and training to mobilize patients receiving mechanical ventilation, excessive sedation, and insufficient staffing, equipment and protocols. Future work aimed at reducing modifiable barriers would be an important next step.

\section{References}

1. Weinert CR, Calvin AD. Epidemiology of sedation adequacy for mechanically ventilated patients in a medical and surgical intensive care unit. Crit Care Med 2007;35:393-401

2. Bailey P, Thomsen GE, Spuhler VJ, et al. Early activity is feasible and safe in respiratory failure patients. Crit Care Med 2007;35:139-45.

3. Thomsen GE, Snow GL, Rodriguez L, et al. Patients with respiratory failure increase ambulation after transfer to an intensive care unit where early activity is a priority. Crit Care Med 2008;36:1119-24.

4. Morris PE, Goad A, Thompson C, et al. Early intensive care unit mobility therapy in the treatment of acute respiratory failure. Crit Care Med 2008;36: 2238-43.

5. Nava S. Rehabilitation of patients admitted to a respiratory intensive care unit Arch Phys Med Rehabil 1998;79:849-54.

6. Schweickert WD, Pohlman MC, Pohlman AS, et al. Early physical and occupational therapy in mechanically ventilated critically ill patients: a randomised controlled trial. Lancet 2009;373:1874-82.

7. Burtin C, Clerckx B, Robbeets C, et al. Early exercise in critically ill patients enhances short-term functional recovery. Crit Care Med 2009;37: 2499-505.

8. Thomas PJ, Paratz JD, Stanton WR, et al. Positioning practices for ventilated intensive care patients: current practice, indications and contraindications. Aust Crit Care 2006;19:122-32.

9. Chang AT, Boots R, Hodges $\mathrm{P}$, et al. Standing with assistance of a tilt table in intensive care: a survey of Australian physiotherapy practice. Aust 7 Physiother 2004;50:51-4.

10. King J, Crowe J. Mobilization practices in Canadian critical care units. Physiother Can 1998;50:206-11.

11. Limperopoulos C, Majnemer A. The role of rehabilitation specialists in Canadian NICUs: a national survey. Phys Occup Ther Pediatr 2002;22:57-72.

12. Norrenberg M, Vincent JL. A profile of European intensive care physiotherapists. Intensive Care Med 2000;26:988-94.

13. Kumar JA, Maiya AG, Pereira D. Role of physiotherapists in intensive care units of India: a multicenter survey. Indian Crit Care Med 2007;11:198-203.

14. Hodgin KE, Nordon-Craft A, McFann KK, et al. Physical therapy utilization in intensive care units: results from a national survey. Crit Care Med 2009;37: 561-8.

15. Appleton RTD, MacKinnon M, Booth MG, et al. Rehabilitation within Scottish intensive care units: a national survey. 7 Intensive Care Soc 2011;12:221-7.

16. Burns KEA, Duffett $M$, Kho ME, et al. A guide for the design and conduct of self-administered surveys of clinicians. CMA7 2008;179:245-52.

17. Sim J, Wright CC. The kappa statistic in reliability studies: use, interpretation, and sample size requirements. Phys Ther 2006;85:257-68.

18. Stevens RD, Dowdy DW, Michaels RK, et al. Neuromuscular dysfunction acquired in critical illness: a systematic review. Intensive Care Med 2007;33: 1876-91.

19. De Jonghe B, Sharshar T, Lefaucheur JP, et al. Paresis acquired in the intensive care unit: a prospective multicentre study. FAMA 2002;288:2859-67. 
20. Leijten FS, De Weerd AW, Poortvliet DC, et al. Critical illness polyneuropathy in multiple organ dysfunction syndrome and weaning from the ventilator. Intensive Care Med 1996;22:856-61.

21. Berek K, Margreiter J, Willeit J, et al. Polyneuropathies in critically ill patients: a prospective evaluation. Intensive Care Med 1996;22:849-55.

22. De Jonghe B, Cook D, Sharshar T, et al. Acquired neuromuscular disorders in critically ill patients: a systematic review. Intensive Care Med 1998;24:1242-50.

23. Needham DM. Mobilizing patients in the intensive care unit: improving neuromuscular weakness and physical function. FAMA 2008;300:1685-90.

24. Needham DM, Korupolu R, Zanni JM, et al. Early physical medicine and rehabilitation for patients with acute respiratory failure: a quality improvement project. Arch Phys Med Rehabil 2010;91:536-42.

25. Nydahl P, Ruhl AP, Bartoszek G, et al. Early mobilization of mechanically ventilated patients: a 1-day point prevalence study in Germany. Crit Care Med 2014;42:1178-86

26. Vazquez A, Arnold S, Johnson MM. Early mobilization of intensive care unit patients: staff attitudes and opinions. Am 7 Respir Crit Care Med 2010;181:A3767.

27. Skinner EH, Berney S, Warrillow S, et al. Rehabilitation and exercise prescription in Australian intensive care units. Physiotherapy 2008;94:220-9.

28. Stiller K. Safety issues that should be considered when mobilizing critically ill patients. Crit Care Clin 2007;23:35-53.

Affiliations: Department of Medicine (Koo), Western University, London, Ont.; Department of Pediatrics (Choong); Department of Medicine (Choong, Cook, Guyatt, Meade); Department of Clinical Epidemiology and Biostatistics (Choong, Cook, Guyatt, Meade), McMaster University, Hamilton, Ont.; Department of Medicine (Herridge, Burns), University of Toronto; Hamilton General Hospital (Newman, Meade), Hamilton, Ont.; University Health Network (Lo), Toronto General Hospital,
Toronto, Ont.; Centre de recherche du Centre hospitalier universitaire de Sherbrooke and Université de Sherbrooke (Lamontagne), Sherbrooke, Que.; Swedish Medical Group (Koo, Priestap, Campbell), Seattle, Wash.

Contributors: All of the authors contributed substantially to study conception and design. Karen Koo and Eileen Campbell collected the data, and Karen Koo drafted the manuscript. All of the authors contributed to data analysis and interpretation, revised the manuscript for important intellectual content, approved the final version submitted for publication and agreed to act as guarantors of the work.

Funding: This study was supported by the Academic Medical Organization of Southwestern Ontario, Lawson Health Research Institute. Deborah Cook is a Canada Research Chair of Research Transfer in Intensive Care.

Acknowledgements: The authors appreciate the contributions by members of the Academy of Critical Care Development, Evaluation, and Methodology, McMaster University, and the Canadian Critical Care Trials Group. The authors thank Valerie Schulz, G. Bryan Young, Brenda Morgan, Cathy Mawdsley, Johanna Fraser and Lisa Moorhouse for participating in clinical sensibility testing; Michelle Kho, Neill Adhikari, Sangeeta Mehta, Andrew Seely, Rob Fowler and Claudio Martin for participating in item reduction; and Raymond Kao for reviewing the English- and French-language questionnaires for conceptual equivalence.

Supplemental information: For reviewer comments and the original submission of this manuscript, please see www.cmajopen.ca/content/4/3/ E448/suppl/DC1 